\title{
The influence of fasting and carbohydrate- enriched drink administration on body water amount and distribution: a volunteer randomized study
}

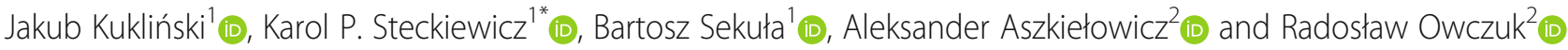

\begin{abstract}
Background: Fasting prior to anesthesia is considered aspiration prophylaxis. However, prolonged food and drink restrictions may increase the risk of other complications. The aim of this study was to assess whether a carbohydrateenriched drink (Nutricia ${ }^{\mathrm{TM}}$ preOp ${ }^{\oplus}$ ), recommended by the enhanced recovery after surgery (ERAS) protocol, can improve body hydration in fasting healthy individuals.

Methods: Measurements were done with the bioelectric impedance analysis with a Fresenius body composition monitor. Body composition, total body water, water distribution, and hemodynamic parameters were measured at the beginning of the study and after $10 \mathrm{~h}$ and $12 \mathrm{~h}$ of fasting. Patients fasted for $10 \mathrm{~h}$ and then were divided into two groups: the control $(n=40)$ and the pre-op group $(n=41)$. The pre-op group received $400 \mathrm{~mL}$ of Nutricia $^{\mathrm{TM}}$ preOp $^{\oplus}$, as suggested in the ERAS guidance. The two-tailed Student's t test was used to compare two groups with normally distributed data and homogenous variances; if variances were heterogeneous, Welch's test was used. The Mann-Whitney $\mathrm{U}$ test was used to compare two groups with non-normal data distribution. $p<$ 0.05 was considered statistically significant.
\end{abstract}

Results: We found no significant differences between the control and pre-op groups regarding body water distribution and body composition. We did not observe significant losses in the total body water after fasting. Also, blood pressure was not affected by fasting.

Conclusion: We have proven that pre-op did not impact either body composition or body water.

Trial registration: ClinicalTrials.gov, NCT04665349. Registered on 11 December 2020-retrospectively registered.

Keywords: Fasting, Bioelectrical impedance analysis, Total body water, Pre-op, Perioperative patient management, Enhanced recovery after surgery (ERAS), Intracellular water, Extracellular water, Dehydration

\section{Introduction}

The current American Society of Anesthesiologists (ASA) guidelines recommend that patients should fast for $6 \mathrm{~h}$ and refrain from drinking clear liquids for $2 \mathrm{~h}$

\footnotetext{
* Correspondence: karol.steckiewicz@gumed.edu.pl

${ }^{1}$ Student Scientific Society, Department of Anesthesiology and Intensive Care, Faculty of Medicine, Medical University of Gdansk, Gdansk, Poland Full list of author information is available at the end of the article
}

before elective surgery (Warner et al. 1999). Excessive fasting is not recommended; however, in many hospitals, patients are required to not eat from the evening before surgery (Chin et al. 2006). Even short-term fasting causes insulin resistance, which leads to hyperglycemia and increases the risk of complications in the postoperative period, and lowers the level of insulin-like growth factor (IGF-1), which impairs wound healing (Nygren

C C The Author(s). 2021 Open Access This article is licensed under a Creative Commons Attribution 4.0 International License, which permits use, sharing, adaptation, distribution and reproduction in any medium or format, as long as you give appropriate credit to the original author(s) and the source, provide a link to the Creative Commons licence, and indicate if changes were made. The images or other third party material in this article are included in the article's Creative Commons licence, unless indicated otherwise in a credit line to the material. If material is not included in the article's Creative Commons licence and your intended use is not permitted by statutory regulation or exceeds the permitted use, you will need to obtain permission directly from the copyright holder. To view a copy of this licence, visit http://creativecommons.org/licenses/by/4.0/ The Creative Commons Public Domain Dedication waiver (http://creativecommons.org/publicdomain/zero/1.0/) applies to the data made available in this article, unless otherwise stated in a credit line to the data. 
2006). This is particularly disadvantageous because the stress response to surgical injury has similar metabolic effects to starvation (Nygren 2006). Moreover, withholding liquid administration may cause dehydration in patients, which increases the risk of hypotension during induction of anesthesia. Unfortunately, direct monitoring of hydration is impossible in the operating room, and only indirect hemodynamic parameters may be used to estimate patient hydration (Pang et al. 2019; Szczepańska et al. 2020). On the other hand, food and fluid restriction causes the stomach to empty, reducing the risk of pulmonary aspiration of gastric contents. It was proven that $\geq 1 \mathrm{~mL} \mathrm{~kg}^{-1}$ of fluid in the stomach may cause a clinically significant risk of aspiration (Bouvet et al. 2019). Thus, intravenous liquids are administered.

There is no consensus on perioperative fluid management among anesthesia providers (Jacob et al. 2008). It is clear that crystalloids are superior to colloids in perioperative fluid therapy (Jacob et al. 2008). In the past, $5 \%$ glucose and $0.9 \%$ sodium chloride solution (named normal saline) were commonly used. It was suggested that $5 \%$ glucose may be beneficial in overcoming insulin resistance, and 5\% glucose was thought to increase intracellular water content; however, these speculations were never confirmed (Chin et al. 2006). Due to their significant disadvantages, these fluids lost their primacy to balanced crystalloids. Although normal saline is isotonic, it is considered a non-balanced crystalloid (Corrêa et al. 2015). It has $154 \mathrm{mEq} \mathrm{L}^{-1}$ of chloride, which is 1.5 times higher than the level in human serum (Corrêa et al. 2015). Additionally, the strong ion difference (SID) of normal saline is much lower than that of serum: $0 \mathrm{mEq}$ $\mathrm{L}^{-1}$ vs. $40 \mathrm{mEq} \mathrm{L}^{-1}$ (Corrêa et al. 2015). In summary, a large volume infusion of normal saline will reduce SID and may cause hyperchloremic acidosis (Corrêa et al. 2015). However, $5 \%$ glucose is an isotonic solution, glucose is rapidly metabolized to water and carbon dioxide after intravenous administration (Chin et al. 2006). Thus, administration of $5 \%$ glucose is equal to the administration of pure water.

Therefore, the enhanced recovery after surgery (ERAS) protocol has been established to increase patient's well-being after surgery. One of the important aspects of ERAS is rational fluid and food restriction prior to anesthesia (Borys et al. 2020; Kaye et al. 2020; Taniguchi et al. 2012). Both ERAS and the European Society for Clinical Nutrition and Metabolism (ESPEN) guidelines recommend oral intake of a carbohydrate-rich drink prior to surgery (Nygren et al. 2013; Weimann et al. 2017).

The aim of this study was to assess whether a carbohydrate-enriched drink (Nutricia ${ }^{\mathrm{TM}}$ preOp $^{\circ}$ ), recommended in ERAS protocols improves body hydration in fasting healthy individuals. We hypothesized that preop would improve body hydration and will not impact body composition. Measurements were done with the bioelectric impedance analysis. To the best of our knowledge, this is the first study of the kind.

\section{Materials and methods}

The study was conducted as a single-center randomized controlled open-label study with balanced randomization conducted in Poland. Study protocol was accepted by Independent Bioethics Committee for Scientific Research at Medical University of Gdansk (resolution 126/2014, from 27th May 2014). The study was carried out according to Good Clinical Practice Guidance (GCP), all precipitants signed written consent. The study took place at the Department of Anesthesiology and Intensive Care of Medical University of Gdansk, Gdansk, Poland, from September 2019 to October 2020. Study design does not contain follow-up. Full study protocol is available from the corresponding author upon request. Study was retrospectively registered at ClinicalTrials.gov (NCT04665349) at 11 December 2020

\section{Participants}

Following approval by the institutional ethics committee and obtaining written informed consent, we recruited 81 adult volunteers of ASA physical status 1 or 2 . The study was performed on healthy individuals. The exclusion criteria were chronic kidney disease, heart failure, phenylketonuria, episodes of hypoglycemia, or other carbohydrate metabolism disorders. The first measurements were taken at 8:00 pm. Body composition was measured in the supine position using two sets of electrodes for unilateral hand and foot measurements. Body mass and blood pressure were also measured. Participants were asked to abstain from food for the next $10 \mathrm{~h}$. They were allowed to drink clear liquids for the next $2 \mathrm{~h}$, after which they had to abstain from all liquids. Second measurements were taken at 6:00 am. Then, participants were divided into two groups, the control and pre-op group, using a computergenerated randomization plan (www.randomization.com). Allocation ratio was 1:1. The control group was not allowed to drink for the next 2 hours, while the pre-op group was given $400 \mathrm{~mL}$ of Nutricia ${ }^{\text {ti }}$ preOp ${ }^{\circ}$. Both groups had to refrain from eating and drinking for the next $2 \mathrm{~h}$. The final measurements were taken at 8:00 am, concluding a 12-h fasting period. Due to lack of norms for body water distribution parameters we were unable to calculate groups sizes ex ante.

\section{Bioelectrical impedance analysis}

Body composition was measured using a Body Composition Monitor (Fresenius Medical Care AG \& Co. KGaA, Germany), which uses non-invasive bioimpedance spectroscopy techniques (Kyle et al. 2004a; Kyle et al. 2004b). Electrodes were placed on the extremities, and an 
alternating current was applied. High-frequency current penetrates cell membranes, while low-frequency current does not. This phenomenon allowed the measurement of electrical resistances of total body water (TBW) and extracellular water $(\mathrm{ECW})$. Those values were then used to calculate clinically relevant parameters, such as ECW, TBW, intracellular water (ICW), adipose tissue mass (ATM), and lean tissue mass (LTM) using two advanced physiological models. All output parameters were validated against reference methods.

\section{Carbohydrate drink}

Nutricia $^{\mathrm{Tm}}$ preOp $^{\oplus}$ is a $0.5-\mathrm{kcal} \mathrm{mL}^{-1}$, clear, carbohydrate drink for patients undergoing elective surgery. All of its energy content comes from carbohydrates, namely, maltodextrin and fructose. A $400 \mathrm{~mL}$ serving contains $50.4 \mathrm{~g}$ of carbohydrates, which is more than the $45 \mathrm{~g}$ recommended by the enhanced recovery after surgery (ERAS) protocol. The drink is isosmotic, with an osmo-

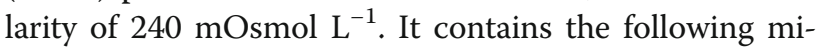
cro- and macro-elements per $100 \mathrm{~mL}: 50 \mathrm{mg}$ of sodium, $122 \mathrm{mg}$ of potassium, $6 \mathrm{mg}$ of chloride, $6 \mathrm{mg}$ of calcium, $1 \mathrm{mg}$ of phosphate, and $1 \mathrm{mg}$ of magnesium.

\section{Statistical analysis}

No interim analyses for efficacy or futility were done. The primary endpoint was changes in the extracellular to intercellular water and the amount of total body water. Outcomes were measured after the study has ended.

Categorical variables are reported by the number and percentage of patients in each category. Continuous variables with a normal probability distribution are presented as the arithmetic mean with standard deviation. For the continuous variables with a different probability distribution, the median and the interquartile range (IQR) are given.

Fisher's exact test was used for the comparison of categorical data. The D'Agostino \& Pearson test was used to assess the normality of the data. For variables with a normal distribution, parametric tests were used; if the normality of the distribution was not confirmed, nonparametric tests were used. The two-tailed Student's $t$ test was used to compare two groups with normally distributed data and homogenous variances; if variances were heterogeneous, Welch's test was used. The MannWhitney $\mathrm{U}$ test was used to compare two groups with
Table 1 Patient characteristics at the beginning of the study. Values are number [\%], median (IQR [range]), or mean (SD)

\begin{tabular}{llll}
\hline Variable & Control $(\boldsymbol{n}=\mathbf{4 0})$ & Pre-op $(\boldsymbol{n}=\mathbf{4 1})$ & $\boldsymbol{p}$ \\
\hline Female & $22[55 \%]$ & $25[61 \%]$ & 0.67 \\
Age (years) & $24.5[23.3-26.0]$ & $25[24.0-28.0]$ & 0.069 \\
Height $(\mathrm{cm})$ & $171.2(9.3)$ & $171.7(8.7)$ & 0.82 \\
Body mass $(\mathrm{kg})$ & $67.0(13.9)$ & $66.8(9.8)$ & 0.93 \\
\hline
\end{tabular}

non-normal data distribution. $p<0.05$ was considered statistically significant.

Data were analyzed with Prism 8 software (GraphPad, USA).

\section{Results}

\section{Participant characteristics}

Eighty-one participants were recruited into the study, and all of them completed the study protocol. Forty participants were randomized into the control group, and forty-one people received carbohydrate drink after $10 \mathrm{~h}$ of fasting. There were no significant differences between groups (Table 1).

\section{Hemodynamic parameters of the participants}

There were no significant differences between systolic blood pressure (SBP) and diastolic blood pressure (DPB) at any of the time points (Table 2). We observed a significant difference in heart rate (HR) between the control and the pre-op group after $12 \mathrm{~h}$ of fasting ( $p=$ 0.0271). HR was higher in the pre-op group (Table 2).

\section{Body composition of the participants}

There were no significant differences between any measured parameters at the 0 -hour and 10-hour time points. After randomization and carbohydrate-enriched drink administration, there were no significant differences between the pre-op and control group (Table 3).

\section{Body water distribution of the participants}

There were no significant differences between body water distribution at the 0-hour and 10-hour time points. After randomization and carbohydrate-enriched drink administration, there were no significant differences between the pre-op and control group (Fig. 1). We did not observe significant dehydration of participants over the course of the study.

Table 2 Comparison of blood pressure and heart rate between groups. Values are median (IQR [range]) or mean (SD)

\begin{tabular}{|c|c|c|c|c|c|}
\hline \multirow[t]{2}{*}{ Variable } & \multirow[t]{2}{*}{$\mathrm{Oh}$} & \multirow[t]{2}{*}{$10 \mathrm{~h}$} & \multicolumn{2}{|l|}{$12 \mathrm{~h}$} & \multirow[t]{2}{*}{$p$} \\
\hline & & & Control $(n=40)$ & Pre-op $(n=41)$ & \\
\hline $\mathrm{SBP}(\mathrm{mmHg})$ & 123 [115.5-135] & 117 [108-125] & 117.5 [103.8-125.8] & 114 [105.6-127.0] & 0.77 \\
\hline $\mathrm{DBP}(\mathrm{mmHg})$ & $79[73.5-86.0]$ & $77[71.5-81.5]$ & $75[71.0-80.8]$ & 75 [69.5-82.0] & 0.67 \\
\hline $\mathrm{HR}(\mathrm{bmp})$ & 78 [70.0-84.0] & 71 [64.0-78.5] & $66.5[59.0-74.0]$ & 72 [66.0-79.0] & 0.03 \\
\hline
\end{tabular}


Table 3 Comparison of body composition between groups. Values are median (IQR [range]) or mean (SD)

\begin{tabular}{|c|c|c|c|c|c|}
\hline \multirow[t]{2}{*}{ Variable } & \multirow[t]{2}{*}{$\mathrm{Oh}$} & \multirow[t]{2}{*}{$10 \mathrm{~h}$} & \multicolumn{2}{|l|}{$12 \mathrm{~h}$} & \multirow{2}{*}{$\begin{array}{l}p \\
\text { (control } \\
\text { vs pre- } \\
\text { op) }\end{array}$} \\
\hline & & & Control $(n=40)$ & Pre-op $(n=41)$ & \\
\hline $\mathrm{BMI}\left(\mathrm{kg} \mathrm{m}^{-2}\right)$ & $22.6(2.8)$ & $22.4(2.7)$ & $22.3(2.9)$ & $22.4(2.5)$ & 0.90 \\
\hline LTI $\left(\mathrm{kg} \mathrm{m}^{-2}\right)$ & $14.5[12.4-17.7]$ & $14.3[12.5-17.1]$ & $15.3[13.1-17.1]$ & $13.4[12.1-17.8]$ & 0.23 \\
\hline LTM (kg) & $41.1[33.8-56.0]$ & $41.1[33.4-54.8]$ & $43.5[34.0-55.3]$ & $40.2[32.9-55.2]$ & 0.43 \\
\hline Fat (kg) & 15.5 [11.7-21.3] & 15.3 [11.3-20.5] & $13.9[11.2-20.5]$ & $17.3[11.4-21.1]$ & 0.21 \\
\hline $\mathrm{FTl}\left(\mathrm{kg} \mathrm{m}^{-2}\right)$ & $7.2[5.8-9.5]$ & $7.1[5.5-9.9]$ & $6.75[5.5-9.4]$ & 7.7 [5.6-10.2] & 0.30 \\
\hline ATM (kg) & 20.6 [15.9-23.4] & 20.9 [15.3-27.9] & 18.9 [15.3-27.9] & 23.5 [15.5-28.7] & 0.22 \\
\hline BCM (kg) & $25.3(8.3)$ & $24.6(8.1)$ & $25.7(8.5)$ & $24.1(8.4)$ & 0.39 \\
\hline
\end{tabular}

\section{Discussion}

We aimed to assess whether the administration of a carbohydrate-enriched drink impacts body water distribution in healthy fasting individuals in this study. Measurements were made with the bioelectrical impedance analysis, which is commonly used for such purposes (Kyle et al. 2004a; Kyle et al. 2004b; Song et al. 2017; Taniguchi et al. 2012; Tsukamoto et al. 2017).
Participants were fasted for $10 \mathrm{~h}$ and the randomized into two groups: the control group, which fasted for 2 more hours, and the pre-op group, which receivedcarbohydrate enriched drink. The baseline hydration of our participants is worth emphasizing, as the majority of the population had E/I ratio values on the higher side of values expected for young adults (Gligoroska et al. 2016). We found no significant differences between the

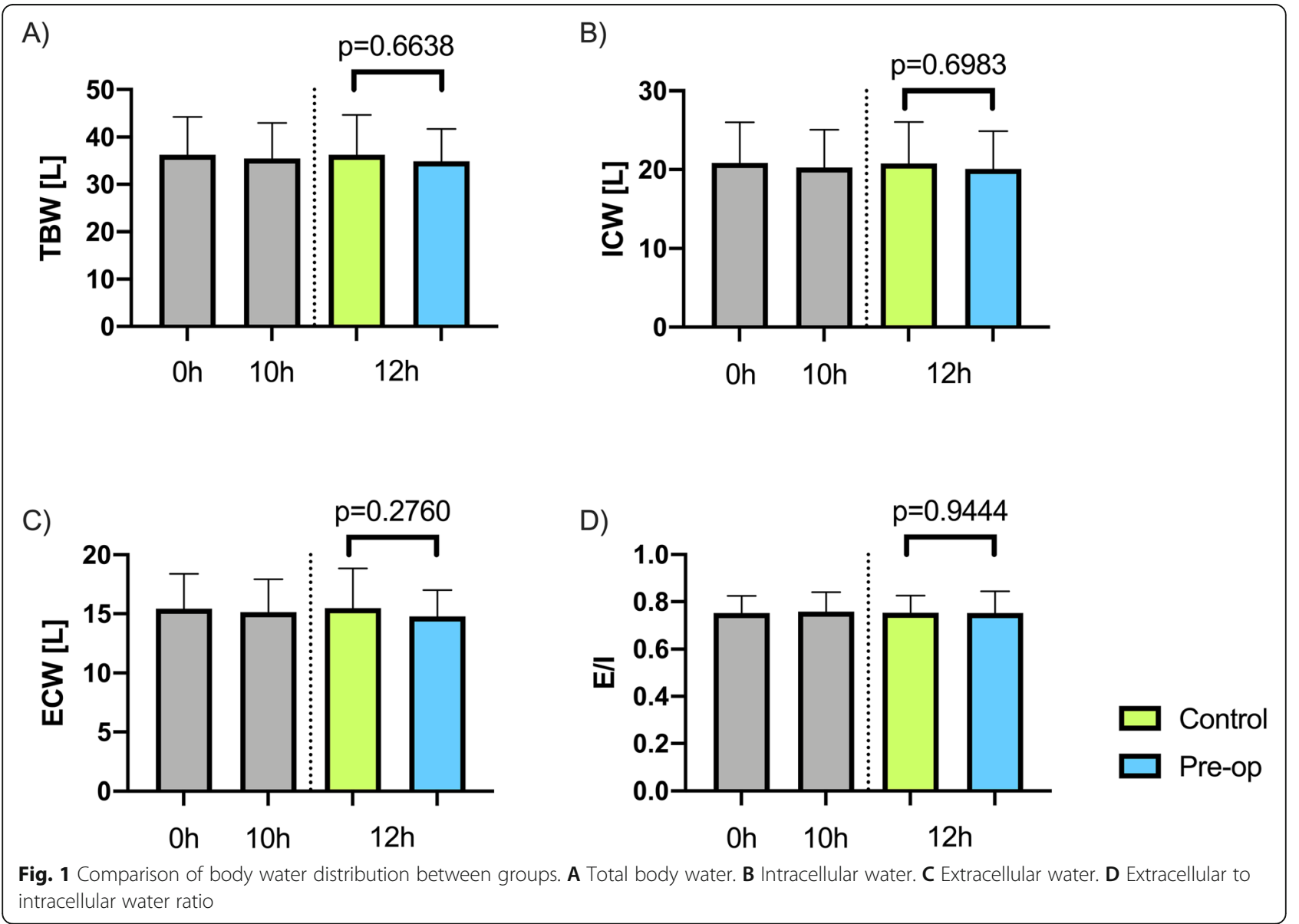


control and pre-op groups regarding body water distribution and body composition. We did not observe significant losses in TBW after fasting.

Other studies also aimed to understand the impact of fasting on body water distribution. Tsukamoto et al. [17] found that there were no differences in TBW, ECW, and ICW in patients with different perioperative fasting periods. In contrast, Taniguchi et al. found that patients with a shortened perioperative fasting time had a smaller decrease in TBW than patients with conventional fasting time (Taniguchi et al. 2012).

Although the carbohydrate drink did not cause any changes in water distribution, there are detrimental metabolic effects of fasting on surgery (Nygren 2006), such as insulin resistance (Soop et al. 2004) and muscle loss (Yuill et al. 2005), that can be alleviated with carbohydrate treatment. Those are associated with prolonged hospital stay, which can be shortened with carbohydrate treatment (Smith et al. 2014). Other beneficial effects include reduction of thirst, hunger, and anxiety (Hausel et al. 2001).

This study has the following limitations. First, we had no actual control of participants' food and fluid intake and had to rely on their compliance, which may have caused alterations in fasting time. Second, we did not forbid smoking; while nicotine causes the release of antidiuretic hormone (Burn 1951), it has no effect on TBW (Vio et al. 1995). Last, we did not measure urine volume. We were unable to perform the power analysis. Ex ante analysis requires precise defined norms for the parameters, and post hoc analysis is biased.

Further studies should focus on the metabolic effects of preoperative carbohydrate treatment, the value of carbohydrates other than maltodextrin, and different routes of administration.

\section{Conclusion}

We determined the impact of a carbohydrate-enriched drink $\left(\mathrm{Nutricia}^{\mathrm{mi}}\right.$ preOp $\left.{ }^{\circ}\right)$ on body composition and body water in fasting healthy individuals. We have proven that pre-op did not impact either body composition or body water.

\section{Abbreviations \\ ASA: American Society of Anesthesiologists; ATM: Adipose tissue mass; BCM: Body cell mass; BMI: Body mass index; DBP: Diastolic blood pressure; E/ I: Extracellular water to intracellular water ratio; ECW: Extracellular water; ERAS: Enhanced recovery after surgery; ESPEN: European Society for Clinical Nutrition and Metabolism; FTI: Fat tissue index; HR: Heart rate; ICW: Intracellular water; LTI: Lean tissue index; LTM: Lean tissue mas; SBP: Systolic blood pressure; SD: Standard deviation; TBW: Total body water}

\section{Acknowledgements}

The authors would like to thank Magdalena A. Wujtewicz MD PhD, Alicja Filipczyk MD, and Jan Stefaniak MD for their help and impact on the study. We also would like to thank the volunteers for their participation.

\section{Authors' contributions}

Study design and conceptualization: AA, RO; data acquisition: JK, KPS, BS; statistical analysis and visualization: KPS; data interpretation: JK, KPS, RO; writing - original draft preparation: JK, KPS; writing - critical review and editing: JK, KPS, BS, AA, RO; supervision and funding: AA, RO. All authors have read and agreed to the published version of the manuscript.

\section{Funding}

Study was funded by resources of the Department of Anaesthesiology and Intensive Therapy of Medical University of Gdansk.

\section{Availability of data and materials}

The data used to support the findings of this study are included within the article or are available from the corresponding author upon request.

\section{Declarations}

Ethics approval and consent to participate

The study protocol was approved by Independent Bioethics Committee for Scientific Research at Medical University of Gdańsk (approval no. NKBBN/126/ 2014). The study was performed in accordance with the ethical standards as laid down in 1964 Declaration of Helsinki and its later amendments. All participates gave informed written consent before enrolment in the study.

\section{Consent for publication}

Not applicable.

\section{Competing interests}

The authors declare that they have no competing interests.

\section{Author details}

${ }^{1}$ Student Scientific Society, Department of Anesthesiology and Intensive Care, Faculty of Medicine, Medical University of Gdansk, Gdansk, Poland. 2Department of Anesthesiology and Intensive Care, Faculty of Medicine, Medical University of Gdansk, Gdansk, Poland.

Received: 3 January 2021 Accepted: 3 June 2021

Published online: 10 August 2021

\section{References}

Borys M, Żurek S, Kurowicki A, Horeczy B, Bielina B, Sejboth J, et al. Implementation of enhanced recovery after surgery (ERAS) protocol in offpump coronary artery bypass graft surgery. A prospective cohort feasibility study. Anaesthesiol Intensive Ther. 2020;52(1):10-4. https://doi.org/10.5114/a it.2020.93160.

Bouvet L, Cercueil E, Barnoud S, Lilot M, Desgranges FP, Chassard D. Relationship between the regurgitated and the aspirated volume of water. A manikin study. Anaesthesiol Intensive Ther. 2019;51(2):121-5. https://doi.org/10.5114/a it.2019.85953.

Burn JH. Antidiuretic effect of nicotine and its implications. Br Med J. 1951; 2(4725):199-201. https://doi.org/10.1136/bmj.2.4725.199.

Chin KJ, Macachor J, Ong KC, Ong BC. A comparison of 5\% dextrose in 0.9\% normal saline versus non-dextrose-containing crystalloids as the initial intravenous replacement fluid in elective surgery. Anaesth Intensive Care. 2006;34(5):613-7.

Corrêa TD, Rocha LL, Pessoa CMS, Silva E, de Assuncao MSC. Fluid therapy for septic shock resuscitation: which fluid should be used? Einstein (Sao Paulo). 2015:462-8 Available from: http://www.scielo.br/scielo.php?script=sci_a rttext\&pid=\$1679-45082015000300462\&lng=en\&nrm=iso\&tlng=en. Instituto Israelita de Ensino e Pesquisa Albert Einstein. Cited 2020 Oct 31.

Gligoroska JP, Todorovska L, Mancevska S, Karagjozova I, Petrovska S. Bioelectrical impedance analysis in karate athletes: BIA parameters obtained with INBODY720 regarding the age. Res Phys Educ Sport Health. 2016;5(2):117-21 Available from: https://go.openathens.net/redirector/leedsmet.ac.uk?url= http\%3A\%2F\%2Fsearch.ebscohost.com\%2Flogin.aspx\%3Fdirect\%3Dtrue\%2 6db\%3Ds3h\%26AN\%3D120814808\%26site\%3Deds-live\%26scope\%3Dsite\%2 6authtype\%3Dathens.

Hausel J, Nygren J, Lagerkranser M, Hellström PM, Hammarqvist F, Almström C, et al. A carbohydrate-rich drink reduces preoperative discomfort in elective surgery patients. Anesth Analg. 2001;93(5):1344-50. https://doi.org/10.1097/ 00000539-200111000-00063 Lippincott Williams and Wilkins. 
Jacob M, Chappell D, Hofmann-Kiefer K, Conzen P, Rehm M. A rational approach to perioperative fluid management. Anesthesiology. 2008;109(4):723-40.

Kaye A, Renschler J, Cramer K, Klein K, Granier A, Hart B, et al. The role of clinical pharmacology in enhanced recovery after surgery protocols: a comprehensive review. Anaesthesiol Intensive Ther. 2020;52(2):154-64. https://doi.org/10.5114/ait.2020.95020.

Kyle UG, Bosaeus I, De Lorenzo AD, Deurenberg P, Elia M, Gómez JM, et al. Bioelectrical impedance analysis - Part I: Review of principles and methods. Clin Nutr. 2004a;23(5):1226-43 Available from: https://pubmed.ncbi.nlm.nih. gov/15380917/. Churchill Livingstone. Cited 2020 Nov 1.

Kyle UG, Bosaeus I, De Lorenzo AD, Deurenberg P, Elia M, Gómez JM, et al. Bioelectrical impedance analysis - Part II: Utilization in clinical practice. Clin Nutr. 2004b;23(6):1430-53 Available from: https://pubmed.ncbi.nlm.nih.gov/1 5556267/. Churchill Livingstone. Cited 2020 Nov 1.

Nygren J. The metabolic effects of fasting and surgery. Best Pract Res Clin Anaesthesiol. 2006;20(3):429-38.

Nygren J, Thacker J, Carli F, Fearon KCH, Norderval S, Lobo DN, et al. Guidelines for perioperative care in elective rectal/pelvic surgery: Enhanced recovery after surgery (ERAS ${ }^{\oplus}$ ) society recommendations. World I Surg. 2013:285-305 Available from: https:/pubmed.ncbinlm.nih.gov/23052796/. Cited 2020 Nov 1.

Pang Q, Hendrickx J, Liu HL, Poelaert J. Contemporary perioperative haemodynamic monitoring. Anaesthesiol Intensive Ther. 2019;51(2):147-58. https://doi.org/10.5114/ait.2019.86279.

Smith MD, Mccall J, Plank L, Herbison GP, Soop M, Nygren J. Preoperative carbohydrate treatment for enhancing recovery after elective surgery. Cochrane Database Syst Rev. 2014 Aug 14;(8):CD009161. https://doi.org/10.1 002/14651858.CD009161.pub2.

Song IK, Kim DH, Kim EH, Lee JH, Kim JT, Kim HS. Efficacy of bioelectrical impedance analysis during the perioperative period in children. J Clin Monit Comput. 2017;31(3):625-30. https://doi.org/10.1007/s10877-016-9881-1 Springer Netherlands.

Soop M, Nygren J, Thorell A, Weidenhielm L, Lundberg M, Hammarqvist F, et al. Preoperative oral carbohydrate treatment attenuates endogenous glucose release 3 days after surgery. Clin Nutr. 2004;23(4):733-41. https://doi.org/10.1 016/j.clnu.2003.12.007.

Szczepańska A, Pluta M, Krzych Ł. Clinical practice in intraoperative haemodynamic monitoring in Poland: a point prevalence study in 31 Polish hospitals. Anaesthesiol Intensive Ther. 2020;52(2):97-104. https://doi.org/10. 5114/ait.2020.95168.

Taniguchi H, Sasaki T, Fujita H. Preoperative management of surgical patients by "Shortened fasting time": A study on the amount of total body water by multi-frequency impedance method. Int J Med Sci. 2012;9(7):567-74. https:// doi.org/10.7150/ijms.4616. Ivyspring International Publisher. Cited 2020 Nov 1.

Tsukamoto M, Hitosugi T, Yokoyama T. Influence of fasting duration on body fluid and hemodynamics. Anesth Prog. 2017;64(4):226-9. https://doi.org/1 0.2344/anpr-65-01-01.

Vio F, Salazar G, Yanez M, Pollastri A, Aguirre E, Albala C. Smoking and its effects on maternal body composition in late pregnancy. Eur J Clin Nutr. 1995;49(4): 267-73.

Warner MA, Caplan RA, Epstein BS, Gibbs CP, Keller CE, Leak JA, et al. Practice guidelines for preoperative fasting and the use of pharmacologic agents to reduce the risk of pulmonary aspiration: Application to healthy patients undergoing elective procedures: a report by the american society of anesthesiologists task force o. Anesthesiology. 1999:896-905 Available from: http://pubs.asahq.org/anesthesiology/article-pdf/90/3/896/396690/0000542-1 99903000-00034.pdf. Lippincott Williams and Wilkins. Cited 2020 Oct 31

Weimann A, Braga M, Carli F, Higashiguchi T, Hübner M, Klek S, et al. ESPEN quideline: Clinical nutrition in surgery. Clin Nutr. 2017;36(3):623-50. https:// doi.org/10.1016/j.clnu.2017.02.013 Cited 2020 Nov 1.

Yuill KA, Richardson RA, Davidson HIM, Garden OJ, Parks RW. The administration of an oral carbohydrate-containing fluid prior to major elective uppergastrointestinal surgery preserves skeletal muscle mass postoperatively - a randomised clinical trial. Clin Nutr. 2005;24(1):32-7. https://doi.org/10.1016/j. clnu.2004.06.009

\section{Publisher's Note}

Springer Nature remains neutral with regard to jurisdictional claims in published maps and institutional affiliations.

Ready to submit your research? Choose BMC and benefit from:

- fast, convenient online submission

- thorough peer review by experienced researchers in your field

- rapid publication on acceptance

- support for research data, including large and complex data types

- gold Open Access which fosters wider collaboration and increased citations

- maximum visibility for your research: over $100 \mathrm{M}$ website views per year

At BMC, research is always in progress.

Learn more biomedcentral.com/submissions 